\title{
Living with Earthquakes in Alaska
}

\section{What to do DURING an earthquake:}
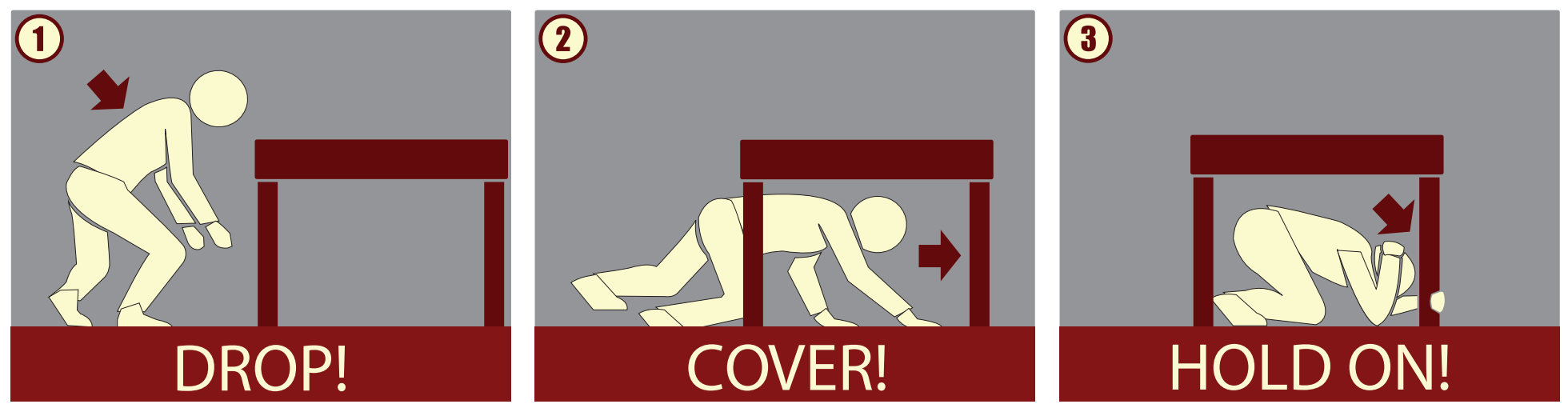

If you are

inside: DO NOT RUN OUTSIDE. Drop, cover (next to a wall if possible), and hold.

outside: Get into the open, away from buildings, then drop and cover.

near the ocean: If shaking lasts for more than 20 seconds (or is strong enough to knock you down) then after the shaking stops SEEK HIGHER GROUND IMMEDIATELY. DO NOT WAIT for an official tsunami warning. Walk quickly and carefully. Expect potential aftershocks.

\section{What to do AFTER an earthquake:}

Check for serious injuries. Do not move a seriously injured person unless necessary. Only use phone in the event of a life-threatening emergency.
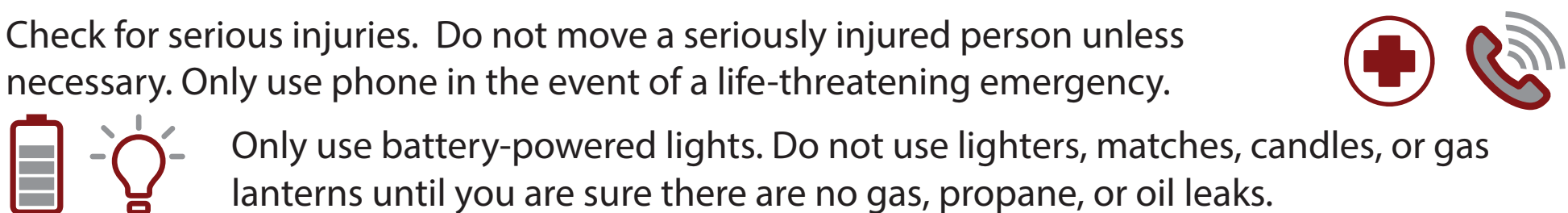

Only use battery-powered lights. Do not use lighters, matches, candles, or gas lanterns until you are sure there are no gas, propane, or oil leaks.

GAS LEAKS: If the area is safe, check tank supports and connecting pipes. Shut off main valves if you smell gas or suspect a broken pipe. Call your gas company for further instructions.

DAMAGED STRUCTURES: Approach all structures with caution. Do not enter damaged buildings or structures. Stay away from downed power lines (even if the power appears to be off) and contact your electric company.

\section{In case of tsunami danger:}

A tsunami may occur at any time. SEEK HIGHER GROUND if you:

Feel a strong earthquake (strong enough to knock you down) or one of long duration (20 or more seconds of shaking).

Hear an official tsunami alert by siren, radio, or television.

See any sudden change in sea level-EVEN IF SEA LEVEL DROPS.

Hear a loud noise coming from the sea.

Seek higher ground these ways, depending on your location (in preference order):

Walk quickly uphill away from the coast or to a tsunami shelter/assembly area.

Go to a third floor or higher in a concrete building.

If you are on a boat, move to deeper water (at least 150 feet deep).

Save yourself, not your possessions. Remember to help neighbors or friends that need special assistance: the elderly, infants, those with mobility needs. 


\section{How to prepare for an earthquake:}

\section{Take actions NOW to reduce injuries and property damage}

ASSESS the potential hazards of your home, work, or school. The safest places are AWAY from heavy furniture, stoves, open shelves, cabinets, mirrors, glass, windows, doors, or pictures IDENTIFY safe places to take cover.

PLAN what to do in the event of an earthquake and/or tsunami. Consider your home, neighborhood, work, and school. What if your family is separated when the event occurs? Choose a family meeting point for each of these scenarios. EVALUATE your tsunami evacuation routes and hazards or obstacles you may encounter. PRACTICE "drop, cover, and hold" drills and evacuating your home and workplace. PREPARE an emergency supply kit for you and your family.

SECURE your household.

\section{Emergency Supply List}

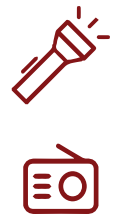

Flashlights with spare batteries. These must be handy! Have one by your bed.

Hand-crank or battery-operated radio. Your vehicle radio is a good alternative.

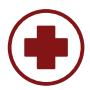

First aid kit and first aid knowledge. Buy a first aid book!

(15) Fire extinguisher. Class " $A B C$ " extinguishers are designed for any type of fire.

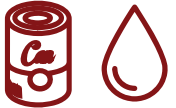

Food (canned or dehydrated) and water for your family AND pets.

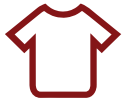

Warm clothes and blankets

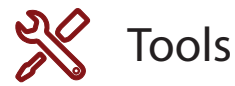

- Special medications or foods for family AND pets.

\section{Secure Your Household:}

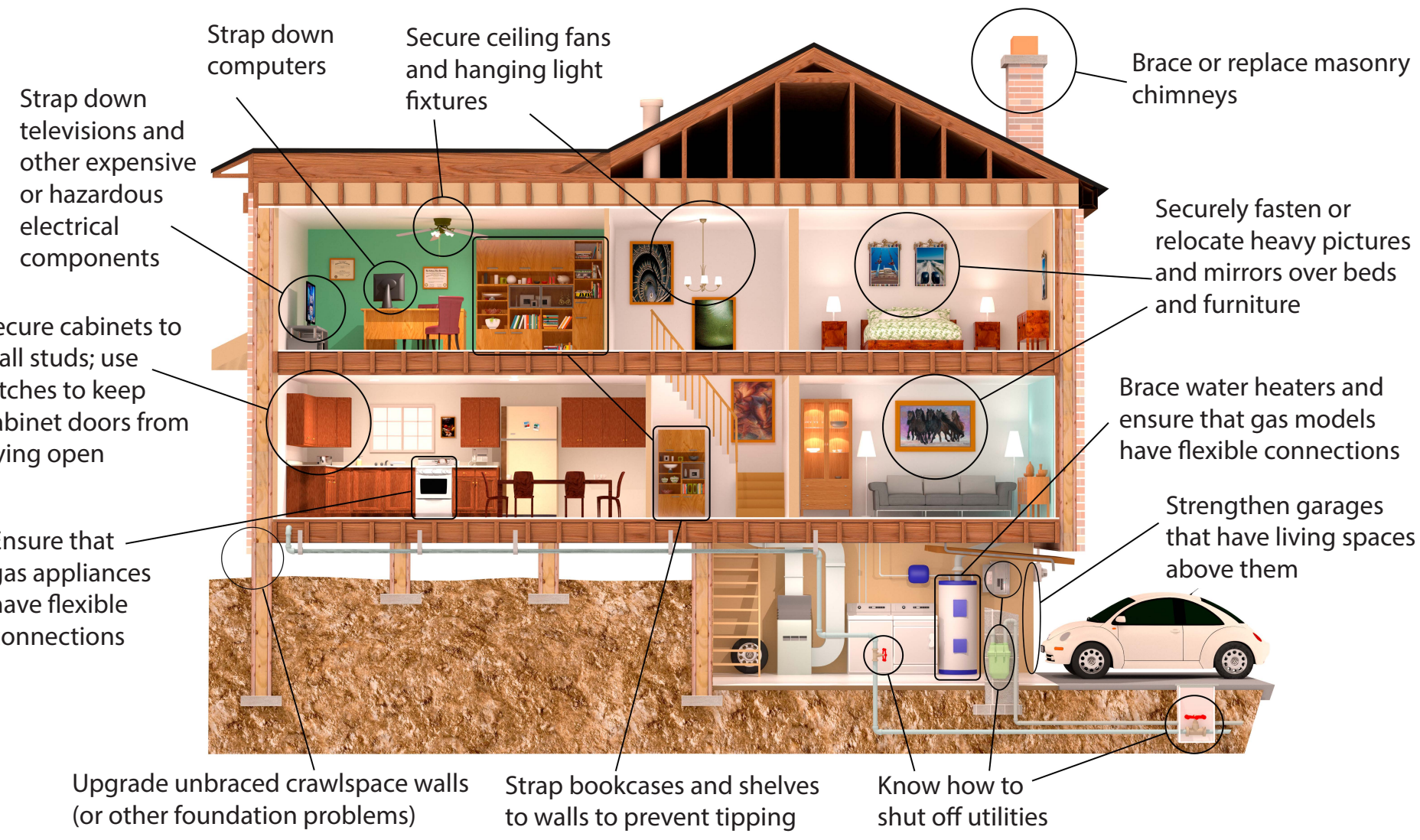

